\title{
Equivalence of the Insulin Sensitivity Index in Man Derived by the Minimal Model Method and the Euglycemic Glucose Clamp
}

\author{
Richard N. Bergman, Rudy Prager, Aage Volund, and Jerrold M. Olefsky \\ Department of Physiology and Biophysics, University of Southern California School of Medicine, Los Angeles, \\ California 90033; Department of Medicine, University of California, San Diego, and the Veterans Administration \\ Medical Center, San Diego, California 92161
}

\begin{abstract}
Studies were done to determine whether the minimal model approach and the glucose clamp measure equivalent indices of insulin action. Euglycemic glucose clamps (glucose, G: $85 \mathrm{mg} / \mathrm{dl}$ ) were performed at two rates of insulin (I) infusion (15 and 40 $\mathrm{mU} / \mathrm{min}$ per $\mathrm{m}^{2}$ ) in 10 subjects (body mass index, BMI, from 21 to $\left.41 \mathrm{~kg} / \mathrm{m}^{2}\right)$. Insulin sensitivity index $\left(\mathrm{S}_{1}\right)$ from clamps varied from 0.15 to 3.15 (mean: $1.87 \pm 0.36 \times 10^{-2} \mathrm{dl} /\left[\mathrm{min}\right.$ per $\left.\mathrm{m}^{2}\right]$ per $\mu \mathrm{U} / \mathrm{ml}$ ), and declined linearly with increasing adiposity (versus BMI: $r=-0.97 ; P<0.001)$. $S_{1}$ from modeling the modified frequently sampled intravenous tolerance test varied from 0.66 to $7.34 \times 10^{-4} \mathrm{~min}^{-1}$ per $\mu \mathrm{U} / \mathrm{ml}$, and was strongly correlated with $S_{\text {IP(clamp) }}(r=0.89 ; P<0.001)$. $S_{1}$ and $S_{\text {IP(clamp) }}$ were similar $(0.046 \pm 0.008$ vs. $0.037 \pm 0.007 \mathrm{dl} / \mathrm{min}$ per $\mu \mathrm{U} / \mathrm{ml}, P>0.35)$; the relation had a slope not different from unity $(1.05 P>0.70)$ and passed through the origin $(P>0.40)$. However, on a paired basis, $S_{1}$ exceeded $S_{\text {IP(clamp) }}$ slightly, due to inhibition of hepatic glucose output during the FSIGT, not included in $\mathbf{S}_{\text {IP(clamp) }}$. These methods are equivalent for assessment of overall insulin sensitivity in normal and insulin-resistant nondiabetic subjects.
\end{abstract}

\section{Introduction}

A consensus has emerged that insulin resistance is an important component in the etiology of glucose intolerance in a variety of metabolic conditions, including obesity (1), aging (2), and noninsulin-dependent diabetes mellitus (3). Thus, it is an important goal to be able to quantify the degree of sensitivity of the tissues to insulin as an indication of the prevalence and/or progress of metabolic disease, and to evaluate the effectiveness of specific therapies. In recent years, a variety of approaches have been put forth to yield either qualitative (4) or quantitative indices of in vivo insulin sensitivity (5). Most recently, the euglycemic clamp of Andres and his colleagues has gained widespread use (6).

While the glucose clamp is widely regarded as the "gold standard" for sensitivity measurement, it remains primarily a laboratory procedure, because it requires sophisticated equipment, highly trained personnel, and it is costly and labor inten-

Address reprint requests to Dr. Bergman. Dr. Prager is on leave from the Second Department of Medicine, University of Vienna, Austria. Dr. Volund is a visiting scientist from the Novo Research Institute, Bagsvaerd, Denmark. 1986.

Received for publication 23 April 1986 and in revised form 3 November

J. Clin. Invest.

(c) The American Society for Clinical Investigation, Inc.

$0021-9738 / 87 / 03 / 0790 / 11 \$ 1.00$

Volume 79, March 1987, 790-800 sive. There remains a need for alternative methods for measuring insulin sensitivity which require less experimental sophistication.

The minimal model methodology has been proposed as a simple alternative to the glucose clamp. With this method, the computer is used to calculate insulin sensitivity from the glucose and insulin dynamics observed during the frequently sampled intravenous glucose tolerance test (FSIGT ${ }^{1} ;$ 7-9).

The question has arisen as to the accuracy of the insulin sensitivity index, $S_{I}$, which is estimated from minimal model analysis of the FSIGT. Donner and his colleagues (10), and Foley et al. (11) reported a weak, marginally significant correlation between insulin sensitivity determined by the minimal model approach and the euglycemic clamp, although the reason for this lack of correlation was not determined. Beard and his colleagues demonstrated that the correlation between these methods became much stronger $(r=0.83)$ when they utilized a modified FSIGT protocol, which entailed the sequential injection of glucose and tolbutamide (12).

The results of Beard and his colleagues suggest that the minimal model approach is an alternative to the euglycemic clamp, in that acceptable estimates of insulin sensitivity may be obtained from either. However, the attractiveness of the minimal model approach would increase if the sensitivity index derived therein were not just related to the clamp-based index, but if, in fact these independently derived measures were equivalent.

In the present study, we measured the insulin sensitivity index in a group of individuals of varying body weight, using both the euglycemic clamp, and the minimal model method. Our goal was to determine whether the model-based sensitivity index was simply a correlate of insulin sensitivity, or whether application of the minimal model yielded the same measure of insulin sensitivity as the euglycemic clamp method.

\section{Methods}

\section{Subjects}

10 subjects were studied (Table I; 9 male, 1 female). Body mass indices varied from 21 to $41 \mathrm{~kg} / \mathrm{m}^{2}$. Thus, 4 subjects were of normal weight, and the remainder were obese. After admission to the Special Diagnosis and Treatment Unit at the San Diego Veterans Administration Hospital, subjects were put on a weight-maintaining diet $(32 \mathrm{kCal} / \mathrm{kg}$ per d) with the following composition: carbohydrate $45 \%$, protein $15 \%$, fat $40 \%$, served in three portions: $1 / 5$ at 8 a.m., $2 / 5$ each at noon and 5 p.m. Each study was performed at least $48 \mathrm{~h}$ after admission, beginning at 7 a.m., after an overnight fast. All 10 patients were subjected to one euglycemic clamp study (insulin infusion rate $40 \mathrm{mU} / \mathrm{min}$ per $\mathrm{m}^{2}$ ) and an additional

1. Abbreviations used in this paper: BMI, body mass index; FSIGT, frequently sampled intravenous glucose tolerance test; GINF, glucose infusion; HGO, hepatic glucose output; $\boldsymbol{R}_{\mathrm{d}}$, glucose uptake; SA, surface area; $\mathrm{S}_{\mathrm{I}}$, insulin sensitivity index; $\mathrm{S}_{\mathrm{IP}(\text { clamp) }}$, clamp-derived insulin sensitivity index; $V_{\mathrm{D}}$, distribution volume. 
Table I. Human Subjects

\begin{tabular}{rllllll}
\hline & Age & Sex & Height & Weight & BMI & Surface area \\
\hline & $y r$ & & $c m$ & $k g$ & $k g / m^{2}$ & $m^{2}$ \\
1 & 28 & M & 173 & 74 & 25 & 1.87 \\
2 & 30 & M & 174 & 65 & 21 & 1.76 \\
3 & 34 & M & 170 & 66 & 23 & 1.78 \\
4 & 37 & M & 181 & 76 & 23 & 1.98 \\
5 & 35 & M & 170 & 80 & 28 & 1.92 \\
6 & 58 & M & 178 & 97 & 31 & 2.18 \\
7 & 53 & M & 191 & 120 & 33 & 2.47 \\
8 & 39 & M & 174 & 121 & 40 & 2.32 \\
9 & 29 & F & 160 & 90 & 35 & 1.98 \\
10 & 38 & M & 184 & 140 & 41 & 2.58 \\
& & & & & & \\
\hline
\end{tabular}

clamp study ( $15 \mathrm{mU} / \mathrm{min}$ per $\mathrm{m}^{2}$ ) was also performed on eight of them. In addition, a single tolbutamide-modified FSIGT was performed on each subject. Studies were randomized, and performed on different days. All experimental protocols were approved by the University of California at San Diego (UCSD) and Veterans Administration (VA) Human Subjects Research Review Committee of the UCSD and VA Medical Center. Informed consent was obtained from all subjects.

\section{Glucose clamp studies}

Euglycemic glucose clamp studies were conducted as previously described (13). Intracatheters were placed in one antecubital vein and a dorsa hand vein cannulated in the retrograde direction. The hand was kept in a heating pad to provide arterialized venous blood. Labeled glucose (3$\left[{ }^{3} \mathrm{H}\right]$ glucose $)$ was injected $(60 \mu \mathrm{Ci})$ and infused $(0.6 \mu \mathrm{Ci} / \mathrm{min})$ thereafter for the entire experiment. $60 \mathrm{~min}$ after tracer infusion was begun, insulin was infused, continuing for $3 \mathrm{~h}$. During the insulin infusion, glucose was maintained at $85 \mathrm{mg} / \mathrm{dl}$ by a variable infusion of $20 \%$ dextrose. The infusion was adjusted according to glucose determinations made every 5 min on a glucose analyzer (Yellow Springs Instruments, Yellow Springs, $\mathrm{OH})$. For calculation of insulin sensitivity, we defined glucose infusion rate as steady state by calculating the average rate over the final $40 \mathrm{~min}$ of insulin infusion. Additional blood samples for determination of insulin and glucose specific activity were collected every 20 min during the glucose clamp.

\section{FSIGT}

After placement of the two intracatheters, four basal samples were collected over $20 \mathrm{~min}$, after which glucose $(0.3 \mathrm{~g} / \mathrm{kg})$ was injected over 1 $\mathrm{min}$, as described (9). An additional injection of tolbutamide (Orinase i.v., Upjohn, Kalamazoo, MI) was given over $20 \mathrm{~s}, 20 \mathrm{~min}$ after glucose. Subjects with body mass index (BMI) $<30 \mathrm{~kg} / \mathrm{m}^{2}$ were given $300 \mathrm{mg}$ tolbutamide; subjects with BMI $>30 \mathrm{~kg} / \mathrm{m}^{2}$ were given $500 \mathrm{mg}$. These doses were equivalent to $4.19 \pm 0.40 \mathrm{mg} / \mathrm{kg}$ (SD) for the lower BMI subjects, and $4.52 \pm 0.80 \mathrm{mg} / \mathrm{kg}$ for the greater BMI subjects $(P>0.40)$. Blood samples $(4 \mathrm{ml})$ were collected at the following times after glucose injection at $t=0: 2,3,4,5,6,8,10,12,14,16,19,22,24,25,27,30$, $40,50,60,70,90,100,120,140,160$, and $180 \mathrm{~min}$. Addition of the tolbutamide injection to the glucose injection protocol decreases the coefficient of variation of the estimate of the insulin sensitivity index $\left(S_{1}\right)$ from 32 to $13 \%$ (reference 14 , assuming a $2 \%$ coefficient of variation in the glucose assay).

\section{Analytical methods}

Glucose kinetics. Specific activity and glucose data were smoothed using the optimal segments method (15), and glucose appearance and disappearance rates were calculated from the derivative form of the Steele relationship (16). Hepatic glucose output was calculated as the difference between total glucose appearance rate and the rate of glucose infusion. Insulin was measured by double antibody radioimmunoassay (17).

\section{Data analysis and statistics}

The insulin sensitivity index was calculated from FSIGT results using the program MINMOD (copyright R. N. Bergman, 1986), which was run on the VAX-750 at the USC Physiology and Biophysics Department (18). This program accepts as input the temporal pattern of plasma insulin during the FSIGT, and must fit a simple (minimal) model of insulindependent glucose utilization to the measured glucose pattern. The model is the simplest mathematical representation that can account for the dynamics of glucose during the FSIGT. The equations of the minimal model are as follows (7): $\mathrm{d} G(t) / \mathrm{d} t=-\left[p_{1}+X(t)\right] G(t)+p_{1} G_{\mathrm{b}}, \mathrm{d} X(t) / \mathrm{d} t$ $=-p_{2} X(t)+p_{3} I(t)$, where $G(t)$ and $I(t)$ are the plasma glucose and insulin concentrations, $X(t)$ is insulin in a compartment remote from plasma, and $p_{1}, p_{2}$, and $p_{3}$ are model parameters. $G_{\mathrm{b}}$ and $I_{\mathrm{b}}$ are preinjection glucose and insulin concentrations. Parameter $p_{1}$ is the fractional disappearance rate of glucose, at basal insulin, independent of the insulin response. Parameters $p_{2}$ and $p_{3}$ determine the kinetics of transport into and out of the remote insulin compartment where insulin action is expressed.

Parameters of the model are estimated from least-squares fitting of the glucose data, and the insulin $S_{1}$ is calculated as the ratio of two of the fitted model parameters $\left(p_{3} / p_{2}\right.$, c.f. Appendix of reference 7$)$. In addition, the fitting procedure yields the apparent volume of distribution of glucose $\left(V_{\mathrm{D}}\right)$ corresponding to the single compartment of the minimal model, and $\mathrm{S}_{\mathrm{G}}\left(=p_{1}\right)$, fractional disappearance rate of glucose independent of the insulin increment. The program MINMOD, adapted for the microcomputer or the VAX computer may be purchased from Dr. R. Bergman.

Standard statistical methods including paired and unpaired $t$ tests, linear regression and correlation analysis were used to examine the relationship between measures of insulin sensitivity from the clamp versus the minimal model methods (19).

\section{Results}

Glucose clamps. The subjects ranged in BMI from 21 to $41 \mathrm{~kg} /$ $\mathrm{m}^{2}$ (Table I). Basal glucose production (equals basal uptake) was relatively constant for all individuals when normalized to body surface area (Table II, $79 \pm 13\left(\right.$ mean \pm SD) $\mathrm{mg} / \mathrm{min}$ per $\mathrm{m}^{2} ; r$ $=0.18$ (NS) with BMI) as would be expected for nondiabetic individuals (20). Unlike basal glucose production, there was a wide range of basal insulin levels in these subjects (range, 7 to $46 \mu \mathrm{U} / \mathrm{ml})$, and basal insulin was correlated with BMI $(r=0.81$, $P<0.01$ ).

Glucose clamps were done at a low $\left[15 \mathrm{mU} /\left(\min\right.\right.$ per $\left.\left.\mathrm{m}^{2}\right)\right]$ or moderate $\left[40 \mathrm{mU} /\left(\min\right.\right.$ per $\left.\left.\mathrm{m}^{2}\right)\right]$ insulin infusion rate. Steady state insulin levels attained were $41 \pm 4$ and $114 \pm 6 \mu \mathrm{U} / \mathrm{ml}$ at the two rates, respectively (mean \pm SE, Table II). Glucose uptake $\left(R_{\mathrm{d}}\right)$ during the 140-180-min period varied among subjects from 68 to $156 \mathrm{mg} / \mathrm{min}$ per $\mathrm{m}^{2}$ at the lower infusion rate; at the higher rate the range was 90 to $340 \mathrm{mg} / \mathrm{min}$ per $\mathrm{m}^{2}$. Glucose uptake at either infusion rate was reduced as BMI increased (correlation with BMI, $r=-0.84$ and -0.90 at the low and moderate rates of insulin infusion).

We have previously defined the insulin sensitivity index for the euglycemic glucose clamp, $\mathrm{S}_{\mathrm{IP}(\mathrm{clamp})}$, as the steady state ratio of the increment in glucose uptake $\left(\Delta R_{\mathrm{d}}\right)$ to the increment in plasma insulin concentration $(\Delta \mathrm{I})$, normalized to the ambient plasma glucose concentration $(G)$ at which the clamp is performed (5): $\mathrm{S}_{\mathrm{IP}(\text { clamp) }}=\Delta R_{\mathrm{d}} /(\Delta \mathrm{I} \times G)$.

In the present studies, we obtained values of plasma insulin and $R_{\mathrm{d}}$ at basal, as well as during the low and moderate dose insulin infusions (Table II). Thus, $\mathrm{S}_{\mathrm{IP}(\mathrm{clamp})}$ could be calculated using the increments in insulin and $R_{\mathrm{d}}$ between any two of these three sets (i.e., basal to 15,15 to 40 , or basal to $40 \mathrm{mU} / \mathrm{min}$ per 


\begin{tabular}{|c|c|c|c|c|c|c|c|}
\hline \multirow[b]{2}{*}{ Subject } & \multicolumn{2}{|l|}{ Basal } & \multicolumn{2}{|c|}{ Low insulin } & \multicolumn{2}{|c|}{ Intermediate insulin } & \multirow[b]{2}{*}{$S_{\text {IPromplo }}$} \\
\hline & Insulin* & $R_{\mathbb{d}}$ & Insulin & $R_{d}$ & Insulin & $R_{d}$ & \\
\hline & & & \multicolumn{2}{|c|}{$15 \mathrm{mU} / \mathrm{m}^{2} \cdot \min$} & \multicolumn{2}{|c|}{$40 \mathrm{mU} / \mathrm{min} \cdot \mathrm{m}^{2}$} & $\begin{array}{l}\times 10^{2} \mathrm{dll} /\left(\mathrm{min} \cdot \mathrm{m}^{2}\right) \\
\operatorname{per} \mu \mathrm{U} / \mathrm{ml}\end{array}$ \\
\hline 1 & 16 & 76 & 51 & 150 & 102 & 277 & 2.75 \\
\hline 2 & 9 & 90 & 45 & 149 & 112 & 340 & 2.86 \\
\hline 3 & 8 & 65 & 35 & 132 & 108 & 328 & 3.09 \\
\hline 4 & 8 & 55 & 31 & 129 & 76 & 237 & 3.15 \\
\hline 5 & 7 & 95 & 38 & 156 & 102 & 284 & 2.34 \\
\hline 6 & 10 & 90 & 33 & 87 & 118 & 235 & 1.58 \\
\hline 7 & 4 & 79 & 27 & 83 & 141 & 265 & 1.72 \\
\hline 8 & 43 & 78 & - & - & 133 & 90 & 0.15 \\
\hline 9 & 12 & 81 & - & - & 109 & 135 & 0.66 \\
\hline 10 & $\underline{46}$ & $\underline{77}$ & $\underline{64}$ & 68 & $\underline{138}$ & $\underline{106}$ & $\underline{0.36}$ \\
\hline Mean \pm SE & $17 \pm 5$ & $79 \pm 4$ & $41 \pm 4$ & $119 \pm 12$ & $114 \pm 6$ & $230 \pm 28$ & $1.87 \pm 0.36$ \\
\hline $\begin{array}{c}\text { Correlation } r= \\
\text { with BMI }\end{array}$ & $\begin{array}{l}0.81 \\
(P<0.01)\end{array}$ & $\begin{array}{l}0.18 \\
\text { (NS) }\end{array}$ & & $\begin{array}{l}-0.84 \\
(P<0.01)\end{array}$ & & $\begin{array}{l}-0.90 \\
(P<0.001)\end{array}$ & $\begin{array}{l}-0.97 \\
(P<0.001)\end{array}$ \\
\hline
\end{tabular}

* Insulin concentration is expressed in $\mu \mathrm{U} / \mathrm{ml} ; R_{\mathrm{d}}$ is expressed in $\mathrm{mg} / \mathrm{min}$ per $\mathrm{m}^{2}$.

$\mathrm{m}^{2}$ ). As an alternative, we could utilize the slope of the best-fit linear regression of steady state $R_{\mathrm{d}}$ on steady state plasma insulin, employing all three data sets (basal, 15 and $40 \mathrm{mU} / \mathrm{min}$ per $\mathrm{m}^{2}$, cf. reference 20). Table III lists the values of $S_{\text {IP(clamp) }}$ calculated these four possible ways for the five lowest-BMI subjects. (We were not able to do this for the more obese subjects because low-dose clamps were not performed on two of them, and in the others there was no measurable effect on $R_{\mathrm{d}}$ at the $15 \mathrm{mU} /$ min per $\mathrm{m}^{2}$ dose.) For the normal subjects, mean calculated $\mathrm{S}_{\mathrm{IP}(\text { clamp })}$ ranged from 2.69 to $2.92 \times 10^{-2} \mathrm{dl} /\left(\mathrm{min}\right.$ per $\left.\mathrm{m}^{2}\right)$ per $\mu \mathrm{U} / \mathrm{ml}$, and there were no significant differences between the individual values for $\mathrm{S}_{\mathrm{IP}(\mathrm{clamp})}$, for the four methods of calculation $(P>0.50$ for all paired comparisons between groups in Table III).

In view of the similarities of $S_{\text {IP(clamp) }}$ values calculated for normal subjects regardless of the insulin interval used, we chose to utilize the 0 to $40 \mathrm{mU} / \mathrm{min}$ per $\mathrm{m}^{2}$ data for calculation of $S_{\text {IP(clamp) }}$ since it could also be used for the obese subjects, and

Table III. Calculation of $S_{I P(\text { clamp })}$ in Normal Subjects Using Different Sets of Clamp Data

\begin{tabular}{|c|c|c|c|c|}
\hline \multirow[b]{2}{*}{ Normal } & \multicolumn{4}{|c|}{$\begin{array}{l}\text { Values }\left(\times 10^{2} \mathrm{dl} \cdot \mathrm{min}^{-1} \mathrm{per} \mu \mathrm{U} / \mathrm{ml}\right) \text { for different insulin infusion } \\
\text { rates }\left(\mathrm{mU} / \mathrm{min} \cdot \mathrm{m}^{2}\right)\end{array}$} \\
\hline & $0-15$ & $15-40$ & $0-40$ & 0-40 regression \\
\hline 1 & 2.48 & 2.93 & 2.75 & 2.76 \\
\hline 2 & 1.93 & 3.35 & 2.86 & 2.92 \\
\hline 3 & 2.92 & 3.16 & 3.09 & 3.11 \\
\hline 4 & 3.79 & 2.82 & 3.15 & 3.10 \\
\hline 5 & 2.31 & 2.35 & 2.34 & 2.34 \\
\hline Mean $\pm \mathrm{SE}^{6}$ & $2.69 \pm 0.32$ & $2.92 \pm 0.17$ & $2.84 \pm 0.14$ & $2.85 \pm 0.14$ \\
\hline
\end{tabular}

* $\mathrm{S}_{\text {IP(damp) }}$ is calculated as the change in $\boldsymbol{R}_{\mathrm{d}}$ divided by the increment in insulin times the ambient glucose concentration $\left[\Delta R_{\mathrm{d}} /(\Delta \mathrm{I} \cdot \mathrm{G})\right]$.

₹ Slope of linear regression for data at 0,15 and $40 \mathrm{mU} / \mathrm{m}^{2} \cdot \mathrm{min}$. Regression coefficient exceeded 0.99 for all regressions shown.

No significant difference was found between any pairs of values of $S_{\text {IP(ctamp) }}$ calculated by the four different techniques $(P>0.5$, paired $t$ test). it was very similar to the value obtained using best-fit linear regression (Table III).

Mean $\mathrm{S}_{\text {IP(clamp) }}$ for all subjects was $1.87 \times 10^{-2} \mathrm{dl} / \mathrm{min}$ per $\mathrm{m}^{2}$ ) per $\mu \mathrm{U} / \mathrm{ml}$ (Table II); however there was a wide range [0.15 to $3.15 \mathrm{dl} /\left(\mathrm{min}\right.$ per $\left.\mathrm{m}^{2}\right)$ per $\mu \mathrm{U} / \mathrm{ml}$. Apparently the range was related to the variability in adiposity. Fig. 1 shows the very strong correlation between BMI and $\mathrm{S}_{\mathrm{IP}(\text { clamp) }}\left(r=-0.97, \mathrm{~S}_{\mathrm{IP}(\text { clamp })}\right.$ $=-0.156 \times \mathrm{BMI}+6.54)$. This correlation could be influenced by age. However, a multiple correlation with age included gave virtually the same relationship between BMI and $\mathrm{S}_{\text {IP(clamp) }}$ $\left(\mathrm{S}_{\mathrm{IP}(\text { clamp) }}=-0.159 \times \mathrm{BMI}+0.008 \times\right.$ age +6.33$)$, with a partial correlation coefficient between $\mathrm{S}_{\mathrm{IP}(\mathrm{clamp})}$ and BMI of -0.97 , while

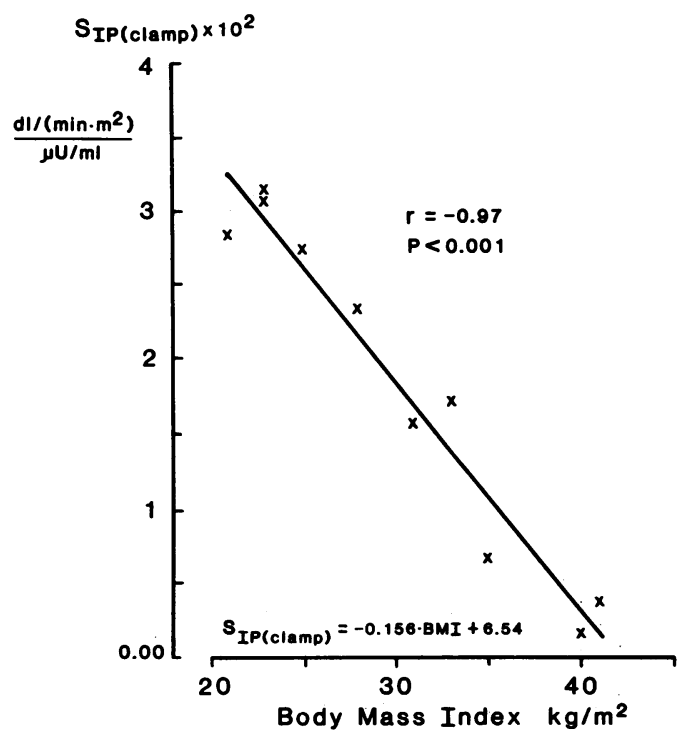

Figure 1. Relationship between insulin sensitivity index from the euglycemic glucose clamps and adiposity. $\mathrm{S}_{\mathrm{IP}(\mathrm{clamp})}$ is defined as $\left(\Delta \boldsymbol{R}_{\mathrm{d}} /\right.$ $\Delta \mathrm{I} \cdot G)$, where $\Delta R_{\mathrm{d}}$ is the change in $R_{\mathrm{d}}$ between basal and at steady state during insulin infusion at $40 \mathrm{mU} / \mathrm{min}$ per $\mathrm{m}^{2}, \Delta \mathrm{I}$ is the increment in insulin, and $G$ is the glucose concentration during the clamps $(85 \mathrm{mg} / \mathrm{dl})$. 
that with age was only 0.30 and was not significant $(P>0.05)$. Thus, in this group of subjects differences in age do not affect the conclusion that as much as $95 \%$ of the variance in insulin sensitivity of this group can be accounted for by their body mass alone. Also, the data in Fig. 1 suggest that the dependence of sensitivity upon adiposity is linear and continuous, rather than decreasing abruptly as adiposity exceeds a "threshold" value.

In addition to the strong correlation with body mass, $\mathrm{S}_{\mathrm{IP}(\mathrm{clamp})}$ was somewhat more weakly (but significantly) negatively correlated with basal insulin concentration $(r=-0.74, P<0.02)$.

FSIGT results. All subjects had a significant first-phase insulin response (Fig. 2, integrated insulin over basal, 0-10 min after glucose injection) which averaged $0.84 \pm 0.13(\mathrm{mU} / \mathrm{ml})$ $\times$ min, and which was independent of adiposity $(r=0.23$, Table IV, NS) Tolbutamide, injected at $20 \mathrm{~min}$, induced a large secondary peak in plasma insulin (Fig. 2). The integrated, 22-180 min above basal response after tolbutamide was $4.38 \pm 1.44(\mathrm{mU} /$
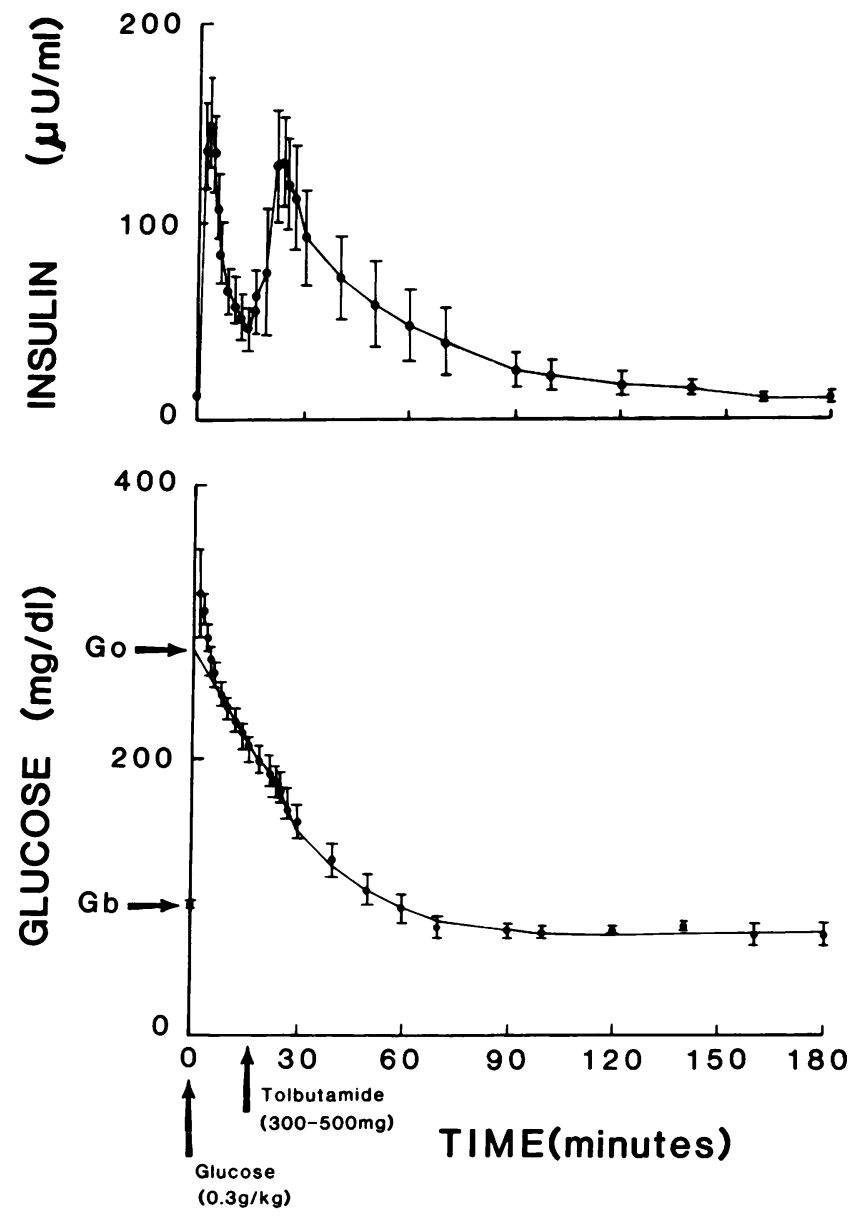

Figure 2. "Modified" frequently-sampled intravenous glucose tolerance test (9). Values on the ordinate ("basal") are the average of 3 fasting values. Dots represent averaged measured values for 10 subjects; solid line in lower panel represents minimal-model fit to the data. Glucose $(0.3 \mathrm{~g} / \mathrm{kg})$ was injected over $1 \mathrm{~min}$ at $t=0$; tolbutamide (300 mg in lean, $500 \mathrm{mg}$ in obese) was injected as a bolus $20 \mathrm{~min}$ later. Note that first seven glucose values are not fit by the model because they are elevated by incomplete mixing in the extracellular fluid. Intersection of the model prediction with the ordinate (predicted value at $t=0$ ignoring mixing phase) is $G_{0}$, the concentration that would have been obtained if extracellular mixing were instantaneous. $G_{\mathrm{b}}$ is the average basal (preinjection) glucose concentration. $\mathrm{ml}) \times \min$. In contrast to the first phase insulin response, tolbutamide-stimulated plasma insulin response increased with adiposity ( $r=0.88$ with BMI, $P<0.001$ ). As discussed, this adiposity-related increment in insulin response could not have been caused by the different dose of tolbutamide in the more obese patients, since the dose per body weight was similar for leaner $\left(B M I<30 \mathrm{~kg} / \mathrm{m}^{2}\right)$ versus more obese $\left(B M I>30 \mathrm{~kg} / \mathrm{m}^{2}\right)$ subjects (see Methods).

Minimal model analysis, like the glucose clamp, revealed a substantial range of insulin sensitivity (Table IV). $\mathrm{S}_{\mathrm{I}}$ varied from $0.66 \times 10^{-4}$ to $7.34 \times 10^{-4} \mathrm{~min}^{-1}$ per $\mu \mathrm{U} / \mathrm{ml}$ (mean $\mathrm{S}_{\mathrm{I}}$ $=3.59 \pm 0.79 \times 10^{-4} \mathrm{~min}^{-1}$ per $\mu \mathrm{U} / \mathrm{ml}$ ). The present report is the first using the tolbutamide modified test in obese subjects, and the range of $S_{I}$ values is consistent with previous reports in normal and obese subjects in whom the previously used protocol (glucose alone) was employed $(8,12)$.

The strong dependence of insulin sensitivity upon adiposity demonstrated with clamp data (Fig. 1) was confirmed with the minimal model method (Fig. 3). As with the glucose clamp, there was a monotonic decline in sensitivity with increasing BMI. The correlation between model-based $\mathrm{S}_{\mathrm{I}}$ and BMI was -0.91 , (Table IV, $P<0.001$ ), somewhat lower than the -0.97 obtained with the clamp. Also, the relationship between basal insulin and insulin sensitivity failed to achieve significance when the modelbased $\mathrm{S}_{\mathrm{I}}$ was used $(r=-0.54, P=0.10)$.

Correlation between glucose clamp and FSIGT results. We found a strong correlation between the insulin sensitivity index measured from the glucose clamps, and that from minimal model analysis of the FSIGT (Fig. $4, r=0.89 ; P<0.001$ ). Of additional interest is the regression equation between these independently measured parameters of insulin action: $S_{I}=1.94 S_{\text {IP(clamp) }}$ -0.03 .

The intercept $(-0.03)$ is not different from $0.00(P>0.9)$. In fact, analysis of the data indicates that an upper $95 \%$ confidence limit for this intercept is less than $20 \%$ of the maximum $\mathrm{S}_{\mathrm{I}}$ value obtained. Thus, from this relatively small sample of patients we were not able to identify any factor, unrelated to insulin sensitivity itself which significantly biased the values of the measures obtained using the minimal model or the glucose clamp.

Equivalence of $S_{I}$ and $S_{I P(c l a m p)}$. The fact that the relationship between $S_{I}$ and $S_{I P(c l a m p)}$ passes through the origin provides the opportunity to determine if these measures are simply correlated with each other, or whether the clamp and minimal model methods are, in fact, measuring the same physiological parameter. To demonstrate equivalence, an additional criterion must be met: not only must the regression line pass through the origin, but in addition, the slope of the relationship between $S_{I}$ and $\mathrm{S}_{\mathrm{IP}(\mathrm{clamp})}$ must be indistinguishable from 1.00.

At first glance it may seem that the relationship shown in Fig. 4 fails to satisfy the second criterion to demonstrate equivalence: the slope of the regression $(1.94 \pm 0.35$, slope $\pm \mathrm{SE})$ is significantly different from $1.00(P<0.05)$. However, this apparent failure to satisfy the second criterion does not indicate inequality between $S_{I}$ and $S_{I P(\text { clamp) }}$ because in Fig. 4 these parameters are not expressed in the same units; $S_{\mathrm{IP}(\text { clamp })}$ is in units of $\mathrm{dl} /(\mathrm{min}$ per $\mathrm{m}^{2}$ ) per $\mu \mathrm{U} / \mathrm{ml} ; \mathrm{S}_{\mathrm{I}}$ is in units of $\mathrm{min}^{-1}$ per $\mu \mathrm{U} / \mathrm{ml}$.

To examine whether the measures are equal (differences only due to random error) it is necessary to convert the measures to identical units. Both parameters can be expressed in terms of change in glucose clearance per change in plasma insulin concentration. To make the conversion for $S_{I}$, it must be multiplied 


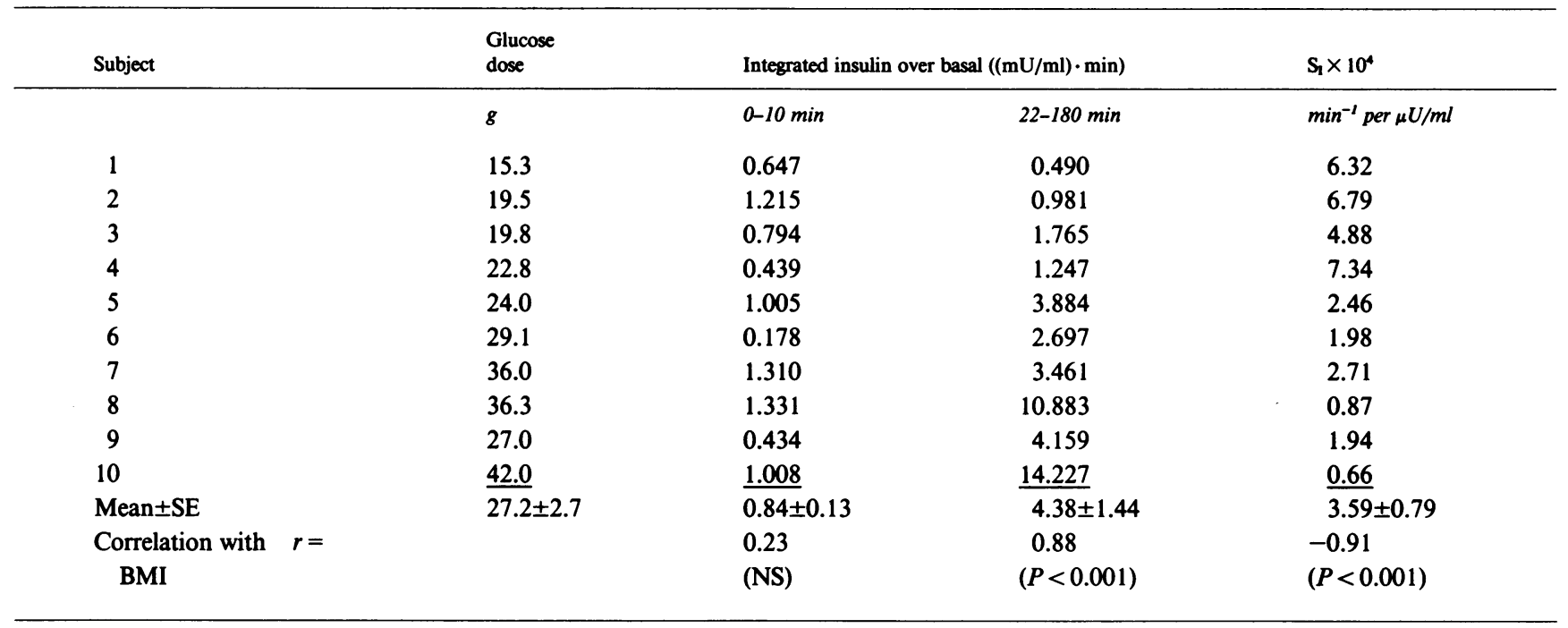

by the distribution volume of glucose $\left(\mathrm{S}_{1} \times V_{\mathrm{D}}\right.$, see Appendix). The minimal model assumes a single extracellular compartment of glucose distribution, and the volume of this compartment $\left(V_{\mathrm{D}}\right)$ is equal to the ratio of the glucose dose to the increment in plasma glucose. This increment is the difference between the post-injection glucose concentration and the basal glucose: $V_{\mathrm{D}}$ $=$ Glucose dose $/\left(G_{0}-G_{\mathrm{b}}\right)$.

The postinjection glucose concentration $\left(G_{0}\right)$ is found when the glucose data is fitted to the minimal model. The glucose data for the initial $8 \mathrm{~min}$ is not fitted by the model because during this interval glucose is mixing in the extracellular fluid (c.f., Fig. 2). When early mixing is ignored, the intercept of the modelpredicted time course of plasma glucose with the ordinate is the predicted glucose concentration that would have been observed

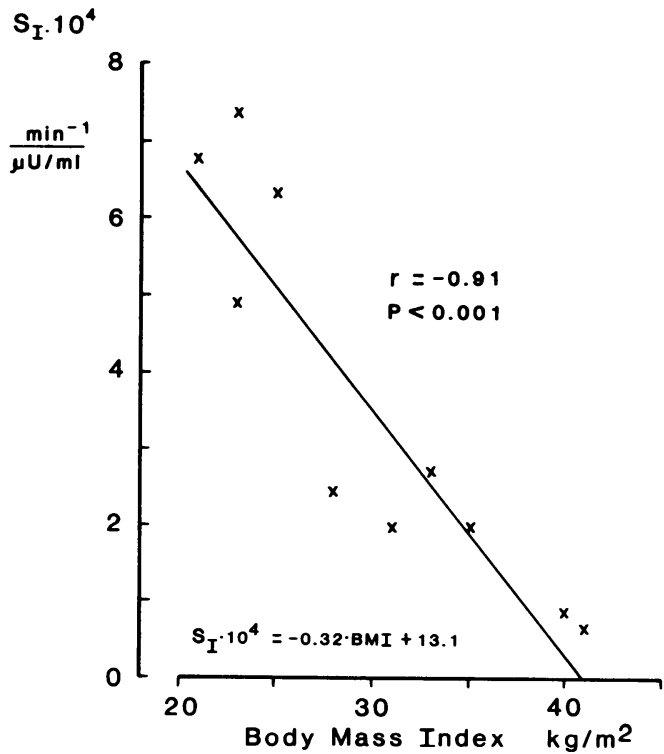

Figure 3. Relation between insulin sensitivity index from the minimal model $\left(\mathrm{S}_{\mathrm{I}}\right)$ and adiposity. $\mathrm{S}_{\mathrm{I}}$ is obtained from fitting the minimal model to the glucose data obtained during the modified FSIGT. if glucose had mixed instantaneously in the 1-compartment "glucose space." This value is $G_{0}$.

The values of $V_{\mathrm{D}}$ for the 10 subjects are calculated in Table $\mathrm{V}$. The volumes ranged between 95.6 and $222 \mathrm{dl}$ in the $10 \mathrm{sub}-$ jects, averaging $16.1 \%$ of body wt. This fraction is considerably less than the entire extracellular glucose space, which has previously been estimated to be $26 \%$ of body wt (21). In fact, the apparent glucose distribution volume was equal to 0.62 multiplied by the estimated total glucose distribution volume.

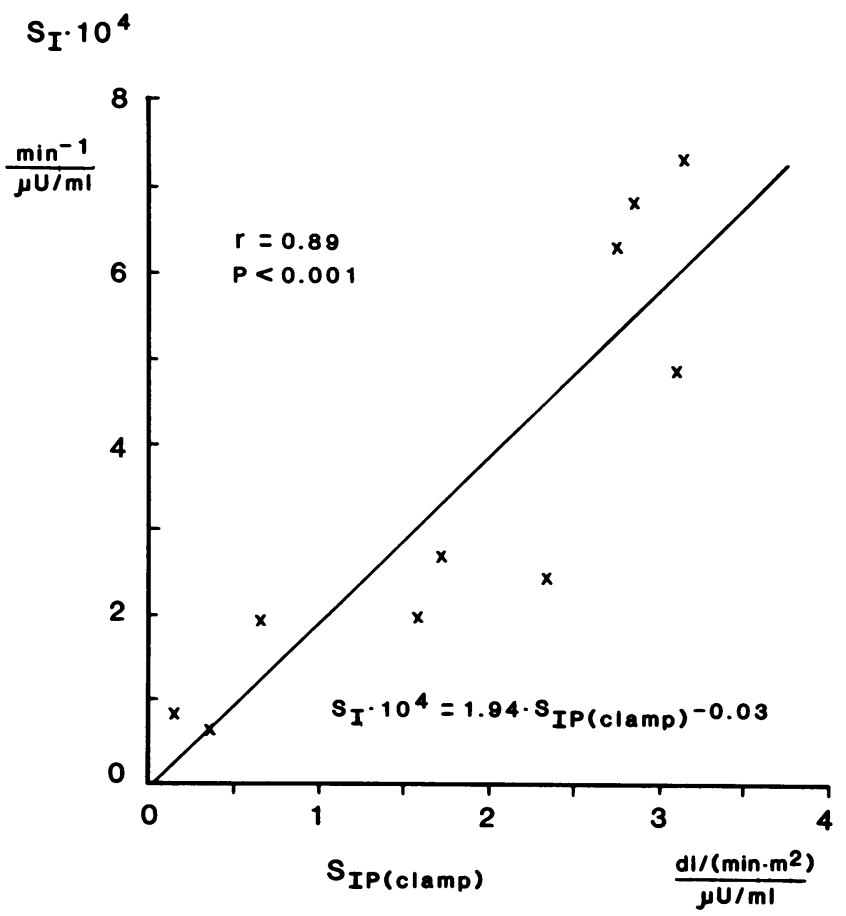

Figure 4. Linear relationship between sensitivity indices obtained from fitting the minimal model to the FSIGT (ordinate) or from the euglycemic glucose clamp data (abscissa). Note that $S_{1}$ and $S_{\text {IP(clamp) }}$ are expressed in different units. Although slope is different from $1.00(P$ $<0.05)$, intercept $(-0.003)$ is not different from $0.00(P>0.90)$. 
Table V. Calculation of Distribution Volume from the Minimal Model Parameters

\begin{tabular}{|c|c|c|c|c|c|}
\hline Subject & $G_{\mathrm{b}}$ & $G_{0}$ & $V_{\mathrm{D}}(\mathrm{dl})$ & $V_{\mathrm{D}}$ & "pool fraction" \\
\hline & $m g / d l$ & $m g / d l$ & {$\left[\right.$ Dose $\left./\left(G_{0}-G_{b}\right)\right]$} & $\%$ body wt & \% body weight/26 \\
\hline 1 & 88 & 289 & 110.0 & 14.9 & 0.57 \\
\hline 2 & 101 & 301 & 97.5 & 15.0 & 0.58 \\
\hline 3 & 95 & 302 & 95.6 & 14.5 & 0.56 \\
\hline 4 & 96 & 282 & 121.9 & 16.0 & 0.62 \\
\hline 5 & 92 & 250 & 151.9 & 19.0 & 0.73 \\
\hline 6 & 100 & 253 & 190.2 & 19.6 & 0.75 \\
\hline 7 & 96 & 275 & 201.1 & 16.8 & 0.65 \\
\hline 8 & 91 & 284 & 188.1 & 15.5 & 0.60 \\
\hline 9 & 104 & 322 & 123.9 & 13.8 & 0.53 \\
\hline 10 & $\underline{108}$ & $\underline{297}$ & $\underline{222.0}$ & $\underline{15.9}$ & $\underline{0.61}$ \\
\hline Mean \pm SE & $97 \pm 2$ & $\overline{279} \pm 9$ & $\overline{150.2} \pm 46.7$ & $\overline{16.1} \pm 0.6 \%$ & $\overline{0.62} \pm 0.02$ \\
\hline
\end{tabular}

To convert $S_{\mathrm{IP}(\text { clamp) }}$ to change in clearance per unit change in plasma insulin it is only necessary to multiply it by body surface area (see Appendix). Thus, to demonstrate equivalence between $S_{I}$ and $S_{I P(\text { clamp) }}$ it is necessary to demonstrate that, on average, $S_{I} \times V_{D}=S_{I P(c l a m p)} \times$ surface area.

Table VI lists both $S_{I}$ and $S_{I P(c l a m p)}$, respectively corrected with distribution volume, or surface area. The product $\mathrm{S}_{\mathrm{I}} \times V_{\mathrm{D}}$ varied from 0.089 to $0.015 \mathrm{dl} / \mathrm{min}$ per $\mu \mathrm{U} / \mathrm{ml}$ (mean $=0.046 \pm 0.008) . \mathrm{S}_{\mathrm{IP}(\text { clamp })} \times$ surface area varied from 0.062 to 0.003 (mean $0.037 \pm 0.007$ ).

The relationship between $S_{I}$ and $S_{I P(c l a m p)}$ expressed in identical units is shown in Fig. 5. Again, the intercept is not different from $0.00(P>0.40)$. The slope of the relationship between these indices of insulin sensitivity was $1.05 \pm 0.19(\mathrm{SE})$. This slope is indistinguishable from $1.00(P>0.7)$. Thus, for the group as a whole, these two measures of insulin sensitivity, $S_{I}$ and $S_{\text {IP(clamp) }}$ apparently satisfied the criterion for equivalence discussed above.

Careful examination of Table VI reveals, however, that on a subject by subject basis there was a modest but significant tendency for $\mathrm{S}_{\mathrm{I}} \cdot V_{\mathrm{D}}$ to exceed $\mathrm{S}_{\mathrm{IP}(\text { clamp) }} \cdot$ surface area (SA) ( $P$ $<0.05$ paired $t$ test). One possible cause of this tendency for a greater sensitivity parameter with the model approach is a dif- ference in definition of sensitivity by the two methods: whereas $S_{\mathrm{IP}(\text { clamp) }}$ measures the effect of insulin to increase total glucose disposal, $S_{I}$ is a measure of the effect of insulin to increase total glucose economy, both by decreasing endogenous production and by enhancement of uptake. Thus, the small difference between these two measures $\left(\mathrm{S}_{\mathrm{I}} \cdot V_{\mathrm{D}}\right.$ averaged $0.009 \mathrm{dl} / \mathrm{min}$ per $\mu \mathrm{U} / \mathrm{ml}$ greater than $\left.S_{\mathrm{IP}(\text { clamp) }} \cdot \mathrm{SA}\right)$ might be explained by the inclusion of inhibition of hepatic glucose production in the model-based measure.

During the euglycemic clamp, the exogenous glucose infusion must compensate for both the decrease in endogenous glucose production and the increase in glucose uptake. Therefore, the rate of glucose infusion is an indication of the total effect of the infused insulin on glucose economy. Thus, we recalculated insulin sensitivity from clamp data using glucose infusion (GINF) in place of $R_{\mathrm{d}}$ for the basal to $40 \mathrm{mU} / \mathrm{m}^{2}$ per min clamp studies. The sensitivity index parameter based on infusion is $S_{I(\text { clamp) }}$, defined as $(\Delta \mathrm{GINF} /(\Delta \mathrm{I} \cdot \mathrm{G}))$. This latter parameter $(X \mathrm{SA})$ averaged $0.052 \pm 0.007 \mathrm{dl} / \mathrm{min}$ per $\mu \mathrm{U} / \mathrm{ml}$ for the 10 subjects, slightly exceeding the model-based value of $0.046 \pm 0.008$ (Fig. 6). Thus, the subtle decrement in the insulin sensitivity measure seen when $R_{\mathrm{d}}$ was used was more than compensated for when total glucose

Table VI. Calculation of Similar Indices of Insulin Sensitivity from FSIGT and Glucose Clamp Results

\begin{tabular}{|c|c|c|c|c|c|c|}
\hline Subject & $\mathrm{S}_{1}^{*}$ & $V_{\mathrm{D}}$ & {$\left[S_{1} \cdot V_{D}\right]$} & $\mathrm{S}_{\mathrm{IP} \text { (camp) }}$ & SA & {$\left[\mathrm{S}_{\mathrm{IP}(\mathrm{comp})} \cdot \mathrm{SA}\right]$} \\
\hline & $\times 10^{4}$ & & & $\times 10^{2}$ & & \\
\hline 1 & 6.32 & 110.0 & 0.070 & 2.75 & 1.87 & 0.051 \\
\hline 2 & 6.79 & 97.5 & 0.066 & 2.86 & 1.76 & 0.050 \\
\hline 3 & 4.88 & 95.6 & 0.047 & 3.09 & 1.78 & 0.055 \\
\hline 4 & 7.34 & 121.9 & 0.089 & 3.15 & 1.98 & 0.062 \\
\hline 5 & 2.46 & 151.9 & 0.037 & 2.34 & 1.92 & 0.045 \\
\hline 6 & 1.98 & 190.2 & 0.038 & 1.58 & 2.18 & 0.034 \\
\hline 7 & 2.71 & 201.1 & 0.054 & 1.72 & 2.47 & 0.043 \\
\hline 8 & 0.87 & 188.1 & 0.016 & 0.15 & 2.32 & 0.003 \\
\hline 9 & 1.94 & 123.9 & 0.024 & 0.66 & 1.98 & 0.013 \\
\hline 10 & 0.66 & 222.0 & $\underline{0.015}$ & 0.36 & 2.58 & $\underline{0.009}$ \\
\hline Mean \pm SE & & & $\overline{0.046} \pm 0.008$ & & & $0.037 \pm 0.007$ \\
\hline
\end{tabular}

* Units are defined as follows: $\mathrm{S}_{\mathrm{l}}, \mathrm{min}^{-1} \operatorname{per} \mu \mathrm{U} / \mathrm{ml} ; V_{\mathrm{D}}, \mathrm{dl} ; \mathrm{S}_{\mathrm{IP}(\mathrm{clamp})}, \mathrm{dl} /\left(\mathrm{min} \cdot \mathrm{m}^{2}\right)$ per $\mu \mathrm{U} / \mathrm{ml} ; \mathrm{SA}$ (surface area), $\mathrm{m}^{2} ; \mathrm{S}_{\mathrm{I}} \cdot V_{\mathrm{D}}$, and $\left(\mathrm{S}_{\mathrm{IP}(\mathrm{clamp})} \cdot \mathrm{SA}\right)$ are in identical units of $\mathrm{dl} / \mathrm{min}$ per $\mu \mathrm{U} / \mathrm{ml}$. 


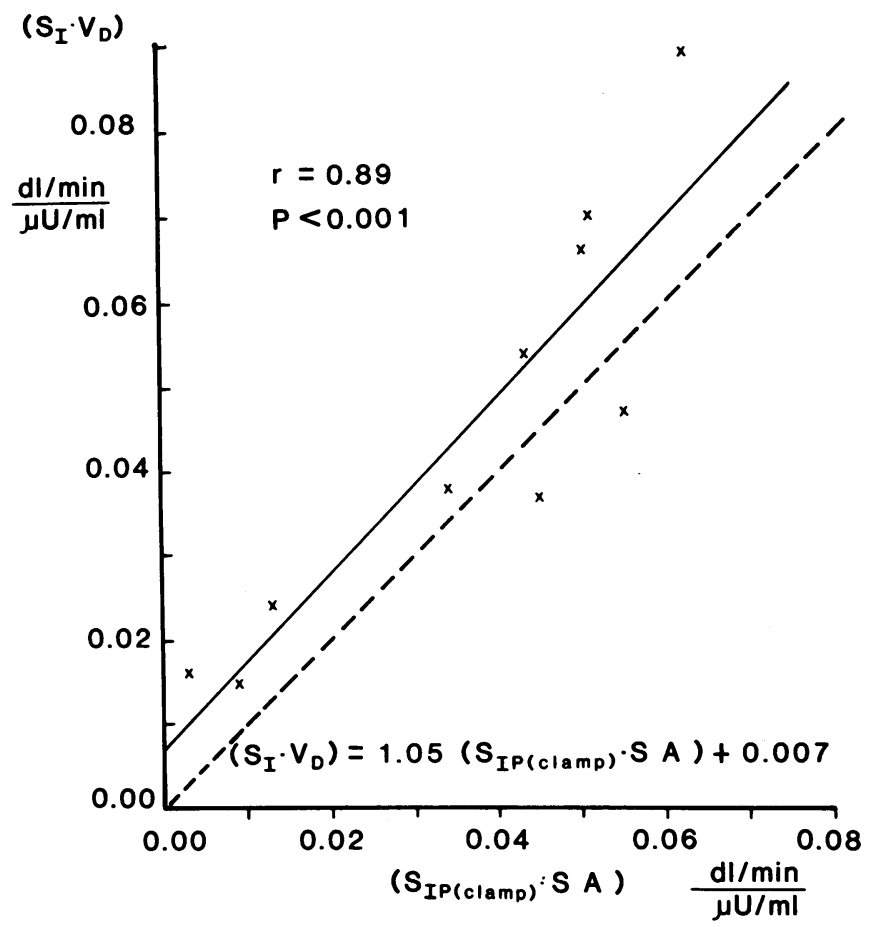

Figure 5. Relationship between sensitivity index measured from the FSIGT (ordinate) and the clamps (abscissa) transformed so that both parameters are expressed in identical units. $\mathrm{S}_{\mathrm{I}}$ is multiplied by glucose distribution volume; $\mathrm{S}_{\mathrm{IP}(\mathrm{clamp})}$ is multiplied by body surface area (see text and Appendix). The slope of the relationship is not different from unity $(P>0.7)$ and the intercept is indistinguishable from $0.00(P$ $>0.40$ ). Dashed line is line of unity slope, zero intercept.

infusion rate was substituted in the clamp-based index of insulin sensitivity. This result is consistent with the notion that the small decrease in $\mathrm{S}_{\mathrm{IP}(\text { (clamp) }} \cdot \mathrm{SA}$ compared to $\mathrm{S}_{\mathrm{I}} \cdot V_{\mathrm{D}}$ was due to the lack of inclusion of liver glucose production inherent in the $\boldsymbol{R}_{\mathrm{d}}$-based, clamp-derived sensitivity index $S_{\mathrm{IP}(\text { clamp) }}$.

The substitution of GINF for $R_{\mathrm{d}}$ did not change the equivalent relationship between the clamp based and model-based sensitivity indices. Slope of the relationship between $S_{\mathrm{I}(\text { (clamp) }}$ and $S_{\mathrm{I}}$ was 0.93 (not different from $1.00, P>0.5$ ); the intercept was -0.003 (not different from $0.00, P>0.5$, data not shown).

\section{Discussion}

Insulin resistance is an important factor underlying the glucose intolerance observed in a variety of metabolic disorders. Among these conditions are some of major epidemiologic importance, such as aging, obesity, and NIDDM, as well as several less prevalent diseases (22-24). Given the benefits that accrue from a better understanding of these conditions, it follows that it is important to develop approaches to assess insulin sensitivity which entail minimum risk and difficulty, but which provide maximum quantitative information. The availability of such approaches has the potential for improved classification of metabolic illness, better prognosis, and earlier detection and intervention.

The euglycemic clamp technique, conceived by Andres et al. (6) and widely exploited by others (c.f. reference 5) remains the most direct approach to assessment of whole-body insulin sensitivity. Using the clamp one may determine a direct doseresponse relationship between the steady state concentration of insulin in plasma and the effect of insulin to suppress endogenous glucose production and enhance glucose uptake. However, as we and others have discussed elsewhere, even these data can be difficult to interpret if comparisons are made among glucose clamp results obtained at different plasma glucose and/or insulin levels (25).

The above considerations have encouraged us to examine alternative approaches to measuring insulin sensitivity. In particular, we have been searching for a method which circumvents some of the aspects of the clamp which have prevented its use outside the clinical research laboratory. The criteria we have attempted to fulfill include the following: (a) no special equipment requirements for the performance of the test, $(b)$ a test that may be performed in an office rather than a laboratory setting (such a test could be used for field studies), (c) reduced labor requirements, and $(d)$ minimization of risk. In addition, and possibly more important, we have desired a methodology for which $(e)$ the attainment of steady state is not a necessity. Finally, it was hoped that the test would provide an accurate assessment of insulin sensitivity which was (within limits) independent of glycemia and insulinemia.

To strive to satisfy these aforementioned criteria we have made use of the digital computer to analyze the dynamics of plasma insulin and glucose observed following glucose injection. The injection of glucose is simple to perform, and virtually risk free. By implementation of the "minimal model" of insulindependent net glucose disappearance on the computer $(5,7-9)$, we have been able to describe the effect of changes in plasma insulin on the postinjection decline of plasma glucose. From the model parameters which emerge from the fitting procedure, we can calculate the $S_{I}$. This sensitivity parameter is a measure of the effect of an increment in plasma insulin to enhance the fractional net disappearance of glucose from an assumed single compartment of extracellular glucose distribution. There is evidence that within the physiological range this parameter is relatively independent of the levels of glycemia and insulinemia at which it is determined $(12,26)$.

The potential of the minimal model approach seemed to us to satisfy most of the requirements we had set down. However, Donner et al. recently reported a very weak correlation ( $r$ $=0.44$ ) between insulin sensitivity from the minimal model analysis, and that observed on a group of subjects using the euglycemic clamp $(10,11)$. Given the demonstrated utility of the clamp, the Donner et al. reports seemed to demonstrate that the minimal model approach violated the accuracy criterion. If $S_{I}$ were indeed an inaccurate index, such a result would severely limit the usefulness of the minimal model approach.

Recent results reported by Beard and his colleagues, in collaboration with some of us (12), have led to a potential explanation for the somewhat disappointing results of Donner et al. We showed that the correlation between the minimal model method and the euglycemic clamp could be considerably strengthened $(r=0.83)$ if the data used as a basis for calculating $S_{I}$ were obtained not from a glucose injection alone, but from a "modified" FSIGT protocol in which tolbutamide was also injected $20 \mathrm{~min}$ after glucose. This modified protocol produced a significantly greater plasma insulin response than glucose alone, and a substantial portion of the insulin response occurred after the $0-8 \mathrm{~min}$ postglucose injection mixing period (27). Because the model requires a substantial effect of insulin after the initial glucose mixing period to calculate a precise measure of insulin sensitivity, addition of the tolbutamide to the injection protocol 
caused a substantial increase in the correlation between modelbased and clamp-based sensitivity (12). However, our earlier studies failed to address the issue of the accuracy of the $S_{I}$ estimate: is $S_{I}$ from the FSIGT simply proportional to clamp-determined insulin sensitivity, or is it in fact equivalent to the sensitivity parameter obtained from the clamp? Demonstrating equivalence represents a validation not only of the FSIGT-based $S_{I}$, but a validation of the minimal model as well.

The present results confirm a strong and highly significant correlation between the insulin sensitivity index measured by the two methods. In fact, in the present studies there was a tendency for the correlation to be higher than was previously found ( $r=0.89$ compared with 0.83 ); presumably this may be explained by the fact that in the present studies we used subjects of widely varying body mass index, and are thus able to compare $S_{I}$ and $\mathrm{S}_{\mathrm{IP}(\text { clamp) }}$ in obesity, while Beard used only normal-weight subjects. The increased variability of adiposity resulted in a wider range of $S_{I}$ in the present studies ( 0.66 to $7.34 \times 10^{-4} \mathrm{~min}^{-1}$ per $\mu \mathrm{U} /$ $\mathrm{ml}$, an 11-fold difference). Assuming that a wider range in insulin sensitivity would be obtained with a greater variability of adiposity, a stronger correlation would be expected, based upon statistical principles (19).

Of particular interest was the negative relationship between insulin sensitivity and obesity in these studies as BMI increased above the normal range (Figs. 1 and 3). While we have insufficient data to determine whether adiposity will lead to relative insulin resistance within the normal limits of body mass index, apparently even mild obesity can have a measurable effect and possibly lead to the negative risk factors associated with diminished sensitivity to the hormone. Further, even after moderate obesity occurs, progression to more severe obesity leads to an additional, measurable decline in insulin action.

More significant than the strong correlation between $S_{\text {IP(clamp) }}$ and $S_{I}$ in the present studies are the following facts: first, that the correlation passed through the origin $(0,0)$; second, that when properly corrected for differences in units, the slope of the relationship was close to unity. In addition, when glucose infusion rate was used as a basis for calculating clamp-based sensitivity, mean values of sensitivity were very similar with both methods $(0.046$ versus $0.052 \mathrm{dl} / \mathrm{min}$ per $\mu \mathrm{U} / \mathrm{ml})$. These results provide strong evidence that the minimal model method and the euglycemic clamp are measuring the same physiological parameter, rather than reflecting different processes which happen to be related to each other. In addition, these results imply that there is no important factor, unrelated to insulin sensitivity, which systematically biases the measurement of either $S_{I}$ or $\mathrm{S}_{\mathrm{I}(\mathrm{clamp})}$. Stated in more general terms, these results demonstrated that (except for random error due to measurement and biological variation between successive measurements) $S_{I}=S_{I P(c l a m p)}$, providing that both parameters are expressed in identical units.

It should be emphasized that for a correlation analysis to be valid, the parameters correlated with each other must be assessed completely independently, i.e., there must not be any common measured variable that contributes to the value of both parameters being correlated. This criterion applies to the variables correlated in Fig. 4 as well as in Fig. 5. Thus, $S_{I}$ and $S_{I P(\text { clamp) }}$ were determined on the same individual, but on different days using entirely independent methods. The independence criterion also applies to the unit-corrected variables correlated in Fig. $3\left(\mathrm{~S}_{I} \cdot V_{\mathrm{D}}\right.$ versus $\mathrm{S}_{\mathrm{IP}(\mathrm{clamp})} \cdot \mathrm{SA}$ ); no factor is common to both measurements. Parameters $S_{I}$ and $V_{D}$ are both calculated from the FSIGT alone; $\mathrm{S}_{\mathrm{IP}(\mathrm{clamp})}$ is determined from the clamp alone, while surface area is estimated from height and weight (28). If this important consideration of the independence of correlated parameters is not obeyed, the correlation coefficient between the different measures of insulin sensitivity could not be taken per se as evidence of equivalence of the two measures.

In the previous study of Beard et al. the regression line did not pass through the origin. A possible reason for the non-zero positive intercept in the earlier study was that sequential euglycemic clamps were performed on a single day, at two levels of insulin infusion. In contrast, in the present experiments the clamps were done at different rates of insulin infusion, on different days. Because the effect of insulin on glucose disposal is long lasting (29), in sequential infusion studies there may be a "memory effect," such that a previous insulin infusion could augment the glucose uptake during a following infusion. Insulin infusion at a low rate followed by a higher one could act to increase $\Delta R_{\mathrm{d}}$ and therefore the value of $\mathrm{S}_{\mathrm{I}(\mathrm{clamp})}$ relative to $\mathrm{S}_{\mathrm{I}}$, and this effect would be progressively more significant at higher insulin infusion rates. This putative memory effect might explain the apparent insulin-dependent bias of $S_{I(\text { clamp) }}$ in the previous study.

One of the primary simplifications implemented in the model is that during the FSIGT, glucose distribution can be described by a single compartment representation, despite evidence for three-compartment distribution of labeled glucose moieties when sufficient time is allotted $(30,31)$. Apparently, since glucose is rapidly normalized during the FSIGT (as compared, for example, to the glucose clamp) little filling of the slow compartments takes place. That equivalent one-compartment representation is adequate to account for FSIGT dynamics is supported by our previous demonstration of single-exponential restitution of the blood glucose, following glucose injection, when the increase in insulin was prevented by somatostatin (32). Thus, during the FSIGT, the glucose distribution system can be represented by an equivalent one-compartment model, with a single distribution volume, $V_{\mathrm{D}}$. Whereas it remains unknown what tissues in the body account for this equivalent single compartment, it remains, as Steele pointed out many years ago (33), a useful conceptual framework for describing glucose dynamics when a relatively short time frame is available for glucose distribution.

Particularly interesting in this regard are the calculated values for $V_{D}$ (Table $V$ ) which were estimated by fitting the minimal model. This apparent volume of distribution, calculated from the increment in plasma glucose (corrected for extracellular mixing), averaged $16.1 \%$ of the body wt. This value represents 0.62 times the total glucose distribution space, prevously estimated to equal $26 \%$ of the body wt (21). What is interesting about the $\mathbf{0 . 6 2}$ factor is that it is almost equal to the so-called "pool fraction" Steele and his colleagues proposed many years ago $(16,21,32)$. Those investigators proposed that one could calculate the rate of glucose production during the non-steady state by assuming a single-compartment distribution volume equal to $65 \%$ of the total distribution volume, when insufficient time was available for glucose equilibration into the entire threecompartment extracellular volume. Their conclusion was validated in the dog under limited conditions by Radziuk and Vranic (34).

The striking equivalence of the apparent distribution volume of the minimal model to the previously validated pool fraction suggests that for the short time periods and limited glucose loads, the single-compartment assumption with the pool fraction sim- 
plification is adequate to represent glucose kinetics. In addition, prediction of the previously validated one-compartment volume can be considered an independent validation of the minimal model.

The ability of the modeling process to yield a measure of the single compartment equivalent glucose $V_{\mathrm{D}}$ in individual subjects (Table V) raises the possibility that $V_{\mathrm{D}}$ itself, estimated from the minimal model fit, could be used in the Steele relation, rather than the "population" value of $0.65 \times 26 \%$ body wt, as is usually done (34). Independent studies will have to be done to determine if using individualized estimates of the pool fraction from the minimal model provides a more accurate assessment of glucose turnover rates from the Steele relationship than using the assumed pool fraction, 0.65 .

Of course, we observed some variation in the relation between $S_{I}$ and $S_{I P(c l a m p)}$ (i.e., individual points did not lie exactly on the line of equality). What cannot be determined from the present study are the factors that contribute to this variability: how much is due to day-to-day variation in insulin sensitivity itself, how much to imprecision in the clamp measurement, and how much to imprecision in the minimal model analysis. The fact that the correlation was not improved markedly by substituting glucose infusion for $R_{\mathrm{d}}$ in the calculation of clamp-based sensitivity indicates that the variance was not due to failure to include liver inhibition in $\mathrm{S}_{\mathrm{IP}(\mathrm{clamp}) \text {. Actual reproducibility determinations will }}$ require future studies of repetitive measures of sensitivity in the same individuals, using the two methods.

Despite the overall equivalence between sensitivity from the clamp and the model, we did find, on a paired basis, a marginally significant tendency for the sensitivity to be higher with the FSIGT than with the clamps, when the values were normalized to identical units (Table VI, Fig. 6). A possible explanation for this is that there is a difference between the definitions of insulin

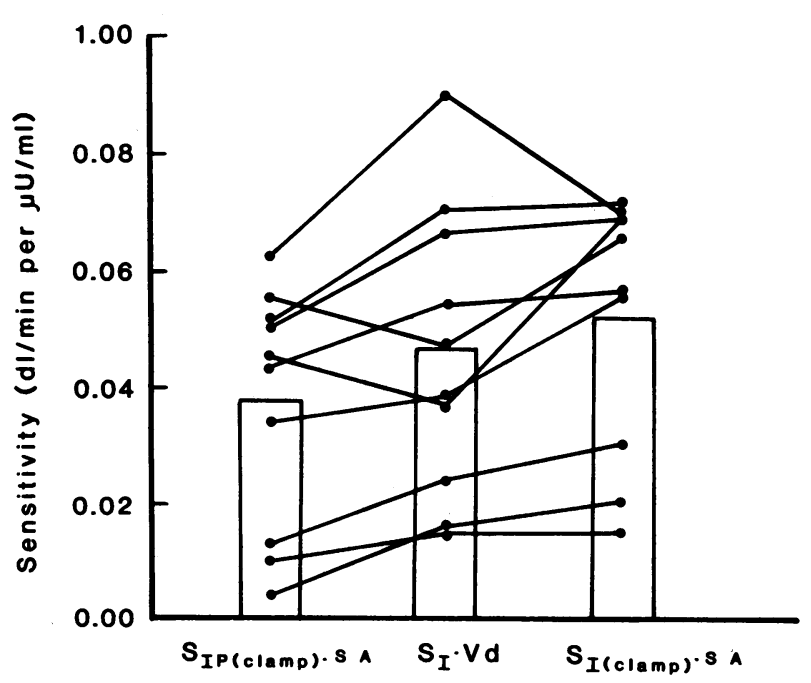

Figure 6. Comparison of three expressions of the insulin sensitivity index in the 10 subjects. All parameters are in units of $\mathrm{dl} / \mathrm{min}$ per $\mu \mathrm{U} / \mathrm{ml}$. $\mathrm{S}_{\mathrm{IP}(\mathrm{clamp})}$ is calculated from euglycemic clamps using $R_{\mathrm{d}}$ only $\left[\mathrm{S}_{\mathrm{IP}(\mathrm{clamp})}=\Delta R_{\mathrm{d}} /(\Delta \mathrm{I} \cdot G)\right] . \mathrm{S}_{\mathrm{I}}$ is from the minimal model $\left(p_{3} /\right.$ $p_{2}$, see Methods), while $S_{\mathrm{I}(\text { clamp) }}$ is calculated from clamp data using glucose infusion data only $\left[\mathrm{S}_{\mathrm{Y}(\text { clamp })}=\Delta \mathrm{GINF} /(\Delta \mathrm{I} \cdot G)\right]$. GINF is the increment in glucose infusion at steady-state, and it is equal to $\left(\Delta R_{\mathrm{d}}-\Delta \mathrm{HGO}\right)$. sensitivity using the clamps, versus minimal model-analyzed FSIGT data. With clamps, we defined sensitivity in terms of the action of insulin to augment glucose utilization $\left(R_{d}\right)$. In the FSIGT, however, model-derived sensitivity is defined in terms of the ability of insulin to both augment glucose utilization and to inhibit hepatic glucose output. Thus, it is the total effect of insulin on the net glucose economy of the body which is represented in $S_{I}$. Therefore, it would not be surprising if, on a subject-by-subject basis, the higher sensitivity found from the FSIGT compared to the glucose clamps may have been due to the inclusion of the liver effect in the definition of insulin sensitivity.

The hypothetical role of inhibition of hepatic glucose output (HGO) to the higher sensitivity measured by FSIGT compared to $S_{\mathrm{IP}(\text { clamp) }}$ is diagramed in Fig. 7. The average increment in sensitivity of FSIGT measurement over the $\boldsymbol{R}_{\mathrm{d}}$ based measurement was $0.009 \mathrm{dl} / \mathrm{min}$ per $\mu \mathrm{U}$ per $\mathrm{ml}$ (Table VI), and this increment was approximately the same for normal and obese subjects (Fig. 7).

The hypothesis that the increment in the model-based compared to the $\boldsymbol{R}_{\mathrm{d}}$-based sensitivity is due to inclusion of HGO inhibition in the former, leads to two predictions.

First, the increment of the FSIGT-based over the $\boldsymbol{R}_{\mathrm{d}}$-based sensitivity can be accounted for by some fraction of the basal rate of HGO, because insulin can do no more than completely inhibit HGO regardless of the concentration achieved during the FSIGT. The increment in the model-based compared to the $\boldsymbol{R}_{\mathrm{d}}$-based sensitivity can be expressed in terms comparable with glucose turnover by multiplying by the clamp glucose concentration $(85 \mathrm{mg} / \mathrm{dl})$ and the increment in insulin due to the 40 $\mathrm{mU} / \mathrm{m}^{2}$ per min insulin infusion (average, $98 \mu \mathrm{U} / \mathrm{ml}$ ), and dividing by the surface area. So transformed, the $0.009 \mathrm{dl} / \mathrm{min}$ per $\mu \mathrm{U} / \mathrm{ml}$ difference is equivalent to $36 \mathrm{mg} / \mathrm{min}$ per $\mathrm{m}^{2}$. The latter

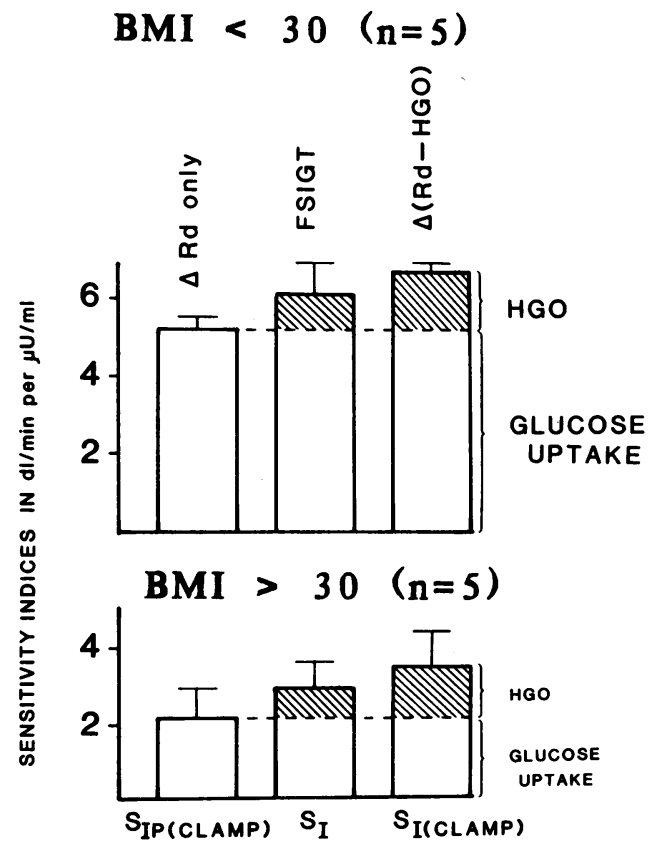

Figure 7. Mean values of three expressions of the insulin sensitivity index (see legend to Fig. 6) for subjects with BMI $<30$ or BMI $>30 \mathrm{~kg}$ / $\mathrm{m}^{2}$. It is hypothesized (see Discussion) that the increment in $\mathrm{S}_{\mathrm{I}}$ or $S_{I(\text { clamp) }}$ over $S_{I P(c l a m p)}$ is due to the fact that the former two indices include insulin inhibition of HGO while the latter does not. 
value is less than the basal glucose production (Table II). Therefore, the extent to which insulin sensitivity measured with the FSIGT exceeds that based upon $R_{\mathrm{d}}$ is consistent with half the basal hepatic glucose output being inhibited during the FSIGT protocol.

Second, the concept that the increment in sensitivity of the FSIGT-based value over the $R_{\mathrm{d}}$-based value is due to partial suppression of HGO during the FSIGT is consistent with the fact that when total glucose infusion $\left(R_{\mathrm{d}}\right.$ increase + HGO decrease) was used as a basis for expressing sensitivity, the value obtained exceeded the FSIGT-based value by $0.006 \mathrm{dl} / \mathrm{min}$ per $\mu \mathrm{U} / \mathrm{ml}\left(24 \mathrm{mg} / \mathrm{min}\right.$ per $\left.\mathrm{m}^{2}\right)$. We expect sensitivity to be higher when infusion rate was the basis for the calculation because the liver was $70-100 \%$ suppressed during the $40 \mathrm{mU} / \mathrm{min}$ per $\mathrm{m}^{2}$ glucose clamps.

Assuming that the inhibition of $\mathrm{HGO}$ is responsible for the larger estimate of insulin sensitivity when the FSIGT is used, compared to $R_{\mathrm{d}}$-based glucose clamps, we can reach certain conclusions regarding the contribution of the insulin-mediated inhibition of HGO, compared to insulin stimulation of glucose uptake. First, in normal individuals only about $17 \%$ of $S_{I}$ is due to insulin inhibition of $\mathrm{HGO}$; the remainder is due to insulin increasing $R_{d}$ (Fig. 7). Therefore, in such individuals it will matter little whether the liver effect is included in the overall sensitivity determination. Second, the contribution of HGO inhibition to sensitivity was similar in obese individuals and normals $(0.008$ versus $0.009 \mathrm{dl} / \mathrm{min}$ per $\mu \mathrm{U} / \mathrm{ml}$ ). Therefore, it would make little difference for comparing insulin sensitivity between normal and obese individuals whether the FSIGT or the $\boldsymbol{R}_{\mathrm{d}}$-based glucose clamp was used. In fact, the absolute difference in sensitivities would be virtually the same (FSIGT: $0.062-0.029=0.033 \mathrm{dl}$ / $\min$ per $\mu \mathrm{U} / \mathrm{ml} ; R_{\mathrm{d}}$-based clamp values: $0.053-0.021=0.032$ $\mathrm{dl} / \mathrm{min}$ per $\mu \mathrm{U} / \mathrm{ml}$ ). Therefore, it appears to be justified to use the parameter $S_{1}$ for assessing insulin action in individuals of differing sensitivity to the hormone, even though $S_{I}$ includes within it the effects of insulin to inhibit endogenous glucose production and to augment glucose utilization.

While the present data is consistent with the idea that the slightly higher index calculated from the FSIGT is due to liver suppression, it is still possible that there is an alternative reason. One possibility is that steady state glucose utilization was not achieved in our clamp experiments, despite $180 \mathrm{~min}$ of insulin infusion. This artifact could result in an underestimate of

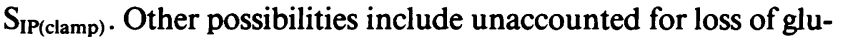
cose via renal excretion which would lead to overestimation of $V_{\mathrm{D}}$. The latter possibility seems unlikely since $<3 \%$ of injected glucose is cleared during an intravenous glucose tolerance test $(35,36)$, and renal clearance would contribute not to $S_{I}$, but the term independent of the insulin response, $S_{G}(32)$. However, whether our supposition is correct that the small differential is due to inclusion of liver suppression in $S_{I}$, but not $S_{I P(\text { clamp) }}$, or whether the differential is due to some other cause remains to be tested experimentally.

In conclusion, the present data demonstrate that minimal model analysis of the frequently sampled intravenous glucose tolerance test yields a measure of insulin sensitivity which is equivalent to the same parameter measured by the euglycemic glucose clamp. The results imply that the measure is dominated by extrahepatic effects of the hormone. Previous poor correlation between these methods was apparently due to suboptimal dynamic testing protocols, rather than inadequacy of the minimal model itself. In addition, the FSIGT is less labor intensive and requires less specialized equipment than the glucose clamp, and the FSIGT yields some information about B-cell function (8). Therefore, the present results indicate that the minimal model method is potentially useful for measuring insulin sensitivity in longitudinal or cross-sectional epidemiologic studies of insulin resistance in nondiabetic individuals, when use of the glucose clamp is not feasible for economic or practical reasons. Of course, it will be necessary to extend validation studies to a wider variety of conditions and to larger populations if general use of the methodology is to be recommended.

\section{Appendix}

While they both reflect insulin sensitivity, $S_{I}$ and $S_{I P(c l a m p)}$ are not directly comparable because they are expressed in different units $\left(S_{\mathrm{I}}\right.$ in $\min ^{-1}$ per $\mu \mathrm{U} / \mathrm{ml}$ and $\mathrm{S}_{\mathrm{IP}(\text { clamp) }}$ in $\mathrm{dl} /\left(\mathrm{min}\right.$ per $\left.\mathrm{m}^{2}\right)$ per $\left.\mu \mathrm{U} / \mathrm{ml}\right)$. To convert them to a common unit it is necessary to use conversion factors which emerge from the method used to estimate them: $S_{1}$ should be converted using parameters estimated for the minimal model approach; $\mathrm{S}_{\mathrm{IP}(\mathrm{clamp})}$ conversion must use factors associated with the euglycemic glucose clamp.

The fundamental difference between $\mathrm{S}_{\mathrm{I}}$ and $\mathrm{S}_{\mathrm{IP}(\mathrm{clamp})}$ as used in the present work is that the former expresses the effect of insulin to increase net fractional disappearance of glucose from the extracellular "glucose space" (i.e., rate of net glucose disappearance divided by amount of glucose in the pool). ${ }^{2}$ The latter represents the effect of insulin to enhance glucose clearance (rate of glucose uptake divided by plasma glucose concentration) per unit body surface area. Thus, these two parameters are normalized to different measures of body "size"; the former to the volume of distribution of glucose of the minimal model itself, the latter to body surface area. However, both parameters can be easily converted to a common index of insulin sensitivity: the effect of a unitary change in insulin to cause a given increment in glucose clearance. ${ }^{3}$ For purposes of discussion, let us define the parameter $S_{c}$, which represents the insulin sensitivity index in units of increment in glucose clearance per unit increment in plasma insulin, expressed in units of deciliters per minute per microunit per milliliter.

Glucose clamp. To reiterate, $\mathrm{S}_{\mathrm{IP}(\text { clamp })}$ is defined as $\left(\Delta R_{\mathrm{d}} /(\Delta \mathrm{I} \times G)\right)$, where $R_{\mathrm{d}}$ is expressed in $\mathrm{mg} / \mathrm{min}$ per unit surface area of the body, $\mathrm{I}$ is in $\mu \mathrm{U} / \mathrm{ml}$, and $G$ is in $\mathrm{mg} / \mathrm{dl}$. The units of $\mathrm{S}_{\mathrm{IP}(\text { clamp })}$ are $\mathrm{dl} /\left(\min\right.$ per $\left.\mathrm{m}^{2}\right)$ per $\mu \mathrm{U} / \mathrm{ml}$, or clearance per unit surface area divided by insulin concentration. To convert $S_{\mathrm{IP}(\mathrm{clamp})}$ to $\mathrm{S}_{\mathrm{c}}$, we simply multiply by the surface area of the individual expressed in $\mathrm{m}^{2}$. Then, for the euglycemic clamp, $\mathrm{S}_{\mathrm{c}}$ will be expressed in $\mathrm{dl} / \mathrm{min}$ per $\mu \mathrm{U} / \mathrm{ml}$ :

$\mathrm{S}_{\mathrm{c}}=\mathrm{S}_{\mathrm{IP( \text {(clamp) }}} \times$ surface area.

Minimal model. The fractional disappearance rate as used in $\mathrm{S}_{\mathrm{I}}$ is the net glucose disappearance rate divided by the glucose "pool" size, where the pool size is the mass of glucose in the single glucose compartment of the minimal model itself. Thus, if we define $V_{\mathrm{D}}$ as the assumed single compartment distribution space with glucose concentration $G$, the net disappearance rate is given as the fractional rate multiplied by $V_{\mathrm{D}} \cdot G$. However, to convert the net rate to glucose clearance it has to be divided by $G$. Thus, $G$ drops out, and to convert $S_{I}$ to $S_{c}$ we simply

2. "Net" glucose disappearance refers to the sum of any decrease in glucose production plus increase in glucose uptake, either of which will act to lower the plasma glucose concentration.

3. Actually, for $S_{1}$ this is given in terms of net glucose clearance; for $\mathrm{S}_{\mathrm{IP}(\mathrm{clamp})}$ this definition is made in terms of absolute glucose clearance (the insulin-induced decrement in HGO is not included). This distinction results in a small but significant difference between $S_{I}$ and $S_{I P(c l a m p)}$ in a given individual (see Discussion). Also, it is important to note that although glucose clearance itself decreases significantly at physiological hyperglycemia (ref. 24 and Table VI of ref. 5) the effect of insulin to enhance glucose clearance (the basis of $\mathrm{S}_{\mathrm{I}}$ ) does not appear to diminish in the physiological range of hyperglycemia (cf. Fig. 28 of ref. 5). 
multiply $\mathrm{S}_{\mathrm{I}}$ by $V_{\mathrm{D}}$ expressed in $\mathrm{dl}$. Then $\mathrm{S}_{\mathrm{c}}$ will be expressed in $\mathrm{dl} / \mathrm{min}$ per $\mu \mathrm{U} / \mathrm{ml}$ :

$\mathrm{S}_{\mathrm{c}}=\mathrm{S}_{\mathrm{I}} \times V_{\mathrm{D}}$.

Summary. Thus, by expressing parameters $\mathrm{S}_{\mathrm{IP}(\mathrm{clamp})}$ and $\mathrm{S}_{\mathrm{I}}$ according to equations $A 1$ and $A 2$, respectively, they are converted to the common parameter $S_{c}$, expressed in $\mathrm{dl} / \mathrm{min}$ per $\mu \mathrm{U} / \mathrm{ml}$. We may demonstrate equality, then, if

$\mathrm{S}_{\mathrm{I}} \times V_{\mathrm{D}}=\mathrm{S}_{\mathrm{IP}(\text { clamp) }} \times$ surface area.

Note that the quantities of the left hand side of equation A3 are measured independently of those on the right hand side. This excludes bias in the statistical comparison of the two methods for measuring $S_{c}$.

\section{Acknowledgments}

We are grateful to Marilyn Ader for her aid in producing the manuscript.

This work was supported by grants from the National Institutes of Health to Drs. Olefsky (AM-33649) and Bergman (AM-29867), and by the Medical Research Service of the Veterans Administration Medical Center, San Diego, CA.

\section{References}

1. Reaven, G. M., J. Moore, and M. Greenfield. 1983. Quantification of insulin secretion and in vivo insulin action in non-obese and moderately obese individuals with normal glucose tolerance. Diabetes. 32: 600-604.

2. DeFronzo, R. A. 1979. Glucose intolerance and aging. Evidence for tissue insensitivity to insulin. J. Clin. Invest. 28:1095-1101.

3. Ginsberg, H., G. Kimmerling, J. M. Olefsky, and G. M. Reaven. 1975. Demonstration of insulin resistance in untreated adult onset diabetic subjects with fasting hyperglycemia. J. Clin. Invest. 55:454-461.

4. Shen, S.-W., G. M. Reaven, and J. W. Farquhar. 1970. Comparison of impedance to insulin-mediated glucose uptake in normal subjects and in subjects with latent diabetes. J. Clin. Invest. 49:2151-2160.

5. Bergman, R. N., D. T. Finegood, and M. Ader. 1985. Assessment of insulin sensitivity in vivo. Endocrine Rev. 6:45-86.

6. Andres, R., R. Swerdloff, T. Pozefsky, and D. Coleman. 1966. Manual feedback technique for the control of blood glucose concentration. In Automation in Analytical Chemistry, J. R. Skeggs, editor. Mediad Inc., New York. 486.

7. Bergman, R. N., Y. Z. Ider, C. R. Bowden, and C. Cobelli. 1979. Quantitative estimation of insulin sensitivity. Am. J. Physiol. 236:E667E677.

8. Bergman, R. N., L. S. Phillips, and C. Cobelli. 1981. Physiologic evaluation of factors controlling glucose tolerance in man. Measurement of insulin sensitivity and beta-cell sensitivity from the response to intravenous glucose. J. Clin. Invest. 68:1456-1467.

9. Bergman, R. N., J. Beard, and M. Chen. 1986. The minimal modeling method. Assessment of insulin sensitivity and B-cell function in vivo. In Methods in Clinical Diabetes Research. J. Larner and S. Pohl, editors. Wiley International, New York. pp. 13-20.

10. Donner, C. C., E. Fraze, Y.-D. I. Chen, C. B. Hollenbeck, J. E. Foley, and G. M. Reaven. 1985. Presentation of a new method for specific measurement of in vivo insulin-stimulated glucose disposal in humans: comparison of this approach with the insulin clamp and minimal model techniques. J. Clin. Endocrinol. Metab. 60:723-726.

11. Foley, J. E., Y.-D. I. Chen, C. K. Lardinois, C. B. Hollenbeck, G. C. Lin, and G. M. Reaven. 1985. Estimates of in vivo insulin action in humans: comparison of the insulin clamp and the minimal model techniques. Horm. Metab. Res. 17:406-409.

12. Beard, J. C., R. N. Bergman, W. K. Ward, J. B. Halter, and D. Porte, Jr. 1986. Study of the insulin sensitivity index in man: correlation between clamp-derived and ivgtt-derived values. Diabetes. 35:362-369.

13. Kolterman, O. G., L. J. Insel, M. Saekow, and J. M. Olefsky. 1980. Mechanisms of insulin resistance in human obesity. Evidence for receptor and postreceptor defects. J. Clin. Invest. 65:1272-1284.
14. Youn, J., Y. Yang, and R. N. Bergman. 1986. Assessment of insulin sensitivity from the IVGTT: improvement of accuracy using modified protocols. Clin. Res. 34:67a. (Abstr.)

15. Finegood, D. T., and R. N. Bergman. 1983. Optimal segments: a method for smoothing tracer data to calculate metabolic fluxes. Am. J. Physiol. 244:E472-479.

16. Steele, R. 1959. Influences of glucose loading and of injected insulin on hepatic glucose output. Ann. NY Acad. Sci. 82:420-430.

17. Desbuquois, B., and G. D. Auerbach. 1971. Use of polyethylene glycol to separate free and antibody bound peptide hormones in radioimmunoassay. J. Clin. Endocrinol. Metab. 33:732-738.

18. Pacini, G., and R. N. Bergman. 1986. MINMOD: A computer program to calculate insulin sensitivity and pancreatic responsivity from the frequently sampled intravenous glucose tolerance test. Computer Methods Progr. Biomed. 23:113-122.

19. Sokal, R. R., and F. J. Rohlf. 1969. Biometry. In The Principles and Practice of Statistics in Biological Research. W. H. Freeman and Co., San Francisco, CA.

20. Kolterman, O. G., G. M. Reaven, and J. M. Olefsky. 1979. Relationship between in vivo insulin resistance and decreased insulin receptors in obese man. J. Clin. Endocrinol. Metab. 48:487-494.

21. Steele, R., J. S. Wall, R. C. de Bodo, and N. Altszuler. 1956. Measurement of size and turnover rate of body glucose pool by the isotope dilution method. Am. J. Physiol. 187:15-24.

22. Ginsberg, H., J. M. Olefsky, and G. M. Reaven. 1975. Evaluation of insulin resistance in patients with primary hyperparathyroidism. Proc. Soc. Exp. Biol. Med. 148:942-945.

23. Bar, R. S., W. R. Levis, M. M. Rechler, L. C. Harrison, C. Siebert, J. Podskalny, J. Roth, and M. Muggeo. 1978. Extreme insulin resistance in ataxia telangiectasia. N. Engl. J. Med. 298:1164-1171.

24. Felber, J. P., and E. Jequier. 1982. Glucose storage deficiency as a cause of insulin resistance in obese hyperinsulinemic diabetes. Int. J. Obesity. 6:131-135.

25. Gottesman, I., L. Mandarino, and J. Gerich. 1984. Use of glucose uptake and glucose clearance for the evaluation of insulin action in vivo. Diabetes. 33:184-191.

26. Beard, J., J. Best, W. K. Ward, and R. N. Bergman. 1982. A glucose-level independent measurement of insulin sensitivity. Diabetes. 31:59A. (Abstr.)

27. Finegood, D. T., R. Watanabe, and R. N. Bergman. 1984. Validation of estimation by optimal segments of the end of extracellular mixing of injected glucose. Fed. Proc. 43:411A. (Abstr.)

28. Ganong, W. F. 1981. Review of Medical Physiology. Lange Medical Publications, Los Altos, CA. 221.

29. Gray, R. S., J. A. Scarlett, J. Griffin, J. M. Olefsky, and O. G. Kolterman. 1982. In vivo deactivation of peripheral, hepatic and pancreatic insulin action in man. Diabetes. 31:929-936.

30. Sherwin, R. S., K. J. Kramer, J. D. Tobin, P. A. Insel, J. E. Liljenquist, M. Berman, and R. Andres. 1974. A model of the kinetics of insulin in man. J. Clin. Invest. 53:1481-1492.

31. Cobelli, C., G. Federspil, G. Pacini, A. Salvan, and C. Scandarelli. 1982. An integrated mathematical model of the dynamics of blood glucose and its hormonal control. Math. Biosci. 58:27-60.

32. Ader, M., G. Pacini, Y. J. Yang, and R. N. Bergman. 1985. Importance of glucose per se to intravenous glucose tolerance: comparison of the minimal model prediction with direct measurements. Diabetes. 34:1092-1103.

33. Steele, R. 1971. Tracer Probes in Steady-State Systems. Charles C Thomas, Springfield, IL.

34. Radziuk, J., K. H. Norwich, and M. Vranic. 1978. Experimental validation of measurements of glucose turnover in nonsteady state. $\mathrm{Am}$. J. Physiol. 3:E84-E93.

35. Amatuzio, D. S., F. L. Stutzman, M. J. Vanderbilt, and S. Nesbitt. 1953. Interpretation of the rapid intravenous glucose tolerance test in normal individuals and in mild diabetes mellitus. J. Clin. Invest. 32: 428-435.

36. Ikkos, D., and R. Luft. 1957. On the intravenous glucose tolerance test. Acta Endocrinol. 25:312-334. 